\title{
Entre el estigma y la comicidad popular: Significaciones del vendedor callejero entre los siglos XVI y XVII
}

\section{Between stigma and popular comedy: Meanings of street vendor between the $16^{\text {th }}$ and $17^{\text {th }}$ centuries}

\author{
Alberto del Campo TEJEDOR \\ Universidad Pablo de Olavide \\ acamtej@upo.es
}

Fecha de recepción: 03-10-2018

Fecha de aceptación: 21-12-2018

\section{RESUMEN}

Fruto de un estudio histórico-cultural sobre el lugar subalterno que ocuparon los vendedores ambulantes entre los siglos XVI y XVII, este artículo analiza las ambiguas significaciones con las que fueron retratados en diferentes campos, y muy singularmente en la literatura, que los asoció a embaucadores, charlatanes, vagabundos, placeras apicaradas, emigrantes miserables y minorías étnico-religiosas. Sin embargo, y a pesar del estigma, sus formas de expresión y especialmente sus pregones cristalizaron como género folclórico-literario, conjugando algunos de los elementos de la cultura cómica popular típica del mundo de la plaza, las ferias y la fiesta.

Palabras clave: vendedor ambulante, estigma, literatura barroca, humor

Topónimos: España, Europa

Período: siglos XVI-XVII

\section{ABSTRACT}

A historical-cultural study of the subaltern position occupied by street vendors between the sixteenth and seventeenth centuries, this article analyses the ambiguous meanings with which they were portrayed in different fields, and most particularly in literature, where they were associated with tricksters, charlatans, vagabonds, roguish stall-holders, miserable emigrants and ethnic-religious minorities. However, despite the stigma, their forms of expression and especially their street cries crystallized as a folkloric-literary genre, conjugating some of the elements of popular comic culture typical of the world of the town square, fairs and festivals.

Key words: street vendor, stigma, baroque literature, humour

Place name: Spain, Europe

Period: $16^{\text {th }}-17^{\text {th }}$ centuries 


\section{INTRODUCCIÓN}

Desde la Antigüedad —como podemos ver por algunas de las sátiras de Marcial ${ }^{1}$ —, el vendedor callejero, y muy particularmente el ambulante, ha gozado de mala reputación, lo que ha sido constatado en diferentes épocas históricas ${ }^{2}$. En la España de los siglos XVI y XVII, la mayoría de estos vendedores pertenecían a las capas pobres de la sociedad; muchos eran extranjeros (franceses), emigrantes de zonas empobrecidas (asturianos, gallegos, cántabros) o formaban parte de minorías étnico-religiosas (gitanos, moriscos, morenos en general); carecían frecuentemente de trabajos estables y se vinculaban al nomadismo; y en sus prácticas de venta bordeaban la legalidad, de ahí que al vendedor callejero, y más aún el que era itinerante, se asemejara al vagabundo, al charlatán, al ladrón, asociaciones simbólicas que aún no han desaparecido en la actualidad, y que explica, por ejemplo, que el vendedor ambulante haya sido un arquetipo frecuentemente utilizado como asustaniños ${ }^{3}$.

Sin embargo, no todo fue estigmatizante: muchos de los que vendían sus productos en la calle tenían un puesto y oficio fijos, y además su práctica evocaba también la sorpresa y excepcionalidad de los productos exóticos que vendían, cuando no encarnaban la utópica imagen de superabundancia, especialmente en días de fiesta. Los pregones, a través de los cuales vociferaban su mercancía, constituían la versión sonora del banquete eterno que alimentaba los sueños utópicos de las clases populares ${ }^{4}$. Sus ademanes y lenguaje eran tachados de groseros y viles, como algunos de los productos que vendían, pero también se asoció su verbo al ingenio, la socarronería y, en general, a una expresividad cómica popular, que la literatura barroca española recreó frecuentemente, retratando a buhoneros, aguadores, placeras, ciegos y otros vendedores callejeros, mezclados con toda suerte de buscavidas apicarados 5 . A menudo, todos ellos vociferan su mercancía en la plaza pública, ruidosa y abigarrada, como ocurre en varios géneros de literatura breve, caso del Entremés de la Plaza de Madrid, atribuido a Lanini, o el Baile de la Plaza Mayor, representado en las Pascuas de 1708 a $1709^{6}$.

Este artículo analiza, con vocación histórico-cultural, las significaciones del vendedor callejero y de sus creaciones verbales prototípicas - los pregones - entre los siglos XVI y XVII, poniendo énfasis en la construcción de una imagen folclórico-literaria vinculada a lo miserable, lo incivilizado, lo peligroso e impuro, pero también a la libertad, el goce, el humor, el ingenio, el desparpajo, en definitiva a un estilo de vida y unas dotes expresivas que le encumbraron como tipo popular, recreado muchas veces en la literatura. Como en anteriores estudios ${ }^{7}$, partimos de que la singular caracterización semiótica de cada tipo se

1 M. V. Marcial, Epigramas, Zaragoza, Institución Fernando el Católico (CSIC), 2003, pp. 93-94.

2 Véase E. Magaldi, "Il commercio ambulante a Pompei", Atti della Academia Pontaniana, 60, 2. 35 (1930); C. Holleran, Shopping in ancient Rome. The Retail Trade in the Late Republic and the Principate, Oxford, Oxford University Press, 2012; P. Chalmeta, El zoco medieval. Contribución al estudio de la historia del mercado, Almería, Fundación Ibn Tafayl de Estudios Árabes, Fundación Cajamar, 2010; L. Fontaine, History of Pedlars in Europe, Durham, Duke University Press, 1996.

3 A. Del Campo y F. C. Ruiz Morales, "Galería de asustaniños de carne y hueso. Miedo y fascinación en torno a las categorías de la anormalidad en Andalucía", Revista de Dialectología y Tradiciones Populares, 70.2 (2015), pp. 547-568.

4 M. Bajtin, La cultura popular en la Edad Media y en el Renacimiento. El contexto de François Rabelais, Madrid, Alianza Universidad, 1995, pp. 164-165.

5 M. E. Perry, Hampa y sociedad en la Sevilla del Siglo de Oro, Sevilla, Ensenada, 2012.

6 M. Herrero, Madrid en el teatro, Madrid, Instituto de Estudios Madrileños, CSIC, 1963, pp. 3-7, 54-63.

7 A. del Campo y R. Cáceres, Historia cultural del flamenco. El barbero y la guitarra, Córdoba, Almuzara, 2013; A. del Campo, 2018, Elogio de la locura sevillana. Necios, inocentes y bufones en la ciudad de la gracia (siglos XV a XIX), Sevilla, Aconcagua. 
gesta tanto en las específicas circunstancias vitales de cada colectivo, como también en las interpretaciones que de ellos se han realizado en un sinfín de textos culturales, en el sentido que le da Clifford Geertz ${ }^{8}$. Aquí privilegiamos uno de ellos: la literatura. Este artículo es una contribución al estudio semiótico de una subcultura y un singular tipo de expresividad, en la línea de lo que propone también Darnton ${ }^{9}$. Finalmente pretende aumentar el conocimiento de los tipos cómicos del Siglo de Oro ${ }^{10}$, en consonancia con los estudios que ponen énfasis en el carácter ambiguo y paradójico de ciertos arquetipos representados en la literatura barroca, como es el caso de los gitanos ${ }^{11}$. Como estos, los vendedores callejeros son figuras ambivalentes, dado que por un lado encarnan al embaucador, al charlatán, al ladrón, pero por otro son muestra de ingenio, desparpajo, humor, lo que les vincula a la polisémica imagen del pícaro.

\section{EL STATUS DEL VENDEDOR CALLEJERO Y AMBULANTE}

Entre los siglos XVI y XVII, los vendedores ambulantes son descritos en toda Europa como gentes en los márgenes de la sociedad ${ }^{12}$. Algunas de las palabras utilizadas para designarles sugieren la baja consideración de este oficio; así el inglés 'pedlar', que podría derivar del latín pedarius ${ }^{13}$. En torno a 1600 la imagen ha cristalizado como un auténtico cliché literario. En La vie généreuse des mercelots gueux et bohémiens (1596), el vendedor ambulante es un engatusador, que incluso usa un lenguaje secreto ${ }^{14}$. En El Criticón (16511657), Gracián compara a los franceses que sacan los cuartos a los españoles engañándoles "con peines, con estuchitos y con trompas de París"15, a lo que hacían los españoles con los indios, cambiando alfileres, espejitos y cascabeles por sus tesoros ${ }^{16}$. Son solo un par de ejemplos que atestiguan el estigma ${ }^{17}$ de los vendedores ambulantes, como el subtipo más denostado dentro de los vendedores callejeros, asociados frecuentemente a la picaresca.

En España, la pésima consideración de la venta callejera se relaciona con el proverbial desdén a los trabajos manuales, y muy particularmente a la compraventa de productos, lo que constituía en los siglos XVI y XVII un arraigado estereotipo. Escribía el historiador italiano Francisco Guicciardini, de estancia en España entre 1512 y 1513 como embajador de la Señoría de Florencia, que los españoles "no se dedican al comercio, considerándolo vergonzoso, porque todos tienen en la cabeza ciertos humos de hidalgo"18. También Andrés Navagero se hacía eco del tópico en 1526. De estancia en Granada, se lamentaba de la expulsión de los moriscos y ensalzaba su laboriosidad, igualmente tópica en su época. Por el contrario, "los españoles, lo mismo aquí que en el resto de España, no son muy

8 C. Geertz, La interpretación de las culturas, Barcelona, Gedisa, 1987, p. 371.

9 R. Darnton, La gran matanza de gatos y otros episodios en la historia de la cultura francesa, México, FCE, 2006.

10 M. Chevalier, Tipos cómicos y Folklore. Siglos XVI y XVII, Madrid, Edi-6, 1982.

11 T. Bergman, "Transversality, criminality, and the gypsy in Spanish baroque teatro breve", Journal of Spanish Cultural Studies, 13:3 (2012), pp. 276-291.

12 L. Fontaine, History of Pedlars...

13 C. Holleran, Shopping in ancient..., p. 196.

14 P. de Ruby, La vie généreuse des mercelots gueux et bohémiens, París, Edicions Allia, 1999.

15 Birimbao, instrumento musical pequeño en forma de herradura.

16 B. Gracián, El Criticón, Madrid, Cátedra, 1996, p. 332.

17 En el sentido que le da Erving Goffman (Estigma. La identidad deteriorada, Buenos Aires, Amorrortu editores, 1970).

18 J. García Mercadal, Viajes de extranjeros por España y Portugal, vol. 1, Salamanca, Junta de Castilla y León, 1999, p. 579. 
industriosos"19, sino que preferirían probar suerte en las Indias o en la guerra. Más de un siglo más tarde, en 1665, el francés Antonio de Brunel ${ }^{20}$ aseguraba que los extranjeros ocupaban en Madrid muchos oficios, como el de aguador, lo que repetía un anónimo viajero en el año 1700:

Desprecian de tal modo el trabajo, que la mayor parte de los artesanos son extranjeros; y se cuentan más de veinte mil franceses en Madrid, y más en Sevilla, la mayor parte de Auvernia. Por eso se dicen todos caballeros ${ }^{21}$.

Aunque muchos de estos trabajos eran ocupados, efectivamente, por emigrantes de Auvernia y Lemosín ${ }^{22}$, el testimonio es exagerado. Sin embargo deja a las claras el estupor que provocaba en los extranjeros la animadversión de los españoles por ciertos trabajos. El de tendero o pequeño comerciante era objeto de un notable desdén. Ya en el siglo XIV, López de Ayala $^{23}$ les satiriza, haciéndose eco de arraigados tópicos acerca del que se gana la vida en algún comercio: jura en falso, adultera las varas y medidas, vende por el doble del precio que le costó, enseña una mercancía y acaba dando al comprador otra de peor calidad, tiene su tienda en oscuridad para ocultar los defectos de los objetos que vende, etc. En teoría la compraventa estaba sujeta a toda una maraña de leyes que supuestamente regulaba quiénes, cómo, dónde, incluso cuándo podían vender cada tipo de género. Así, por ejemplo, un auto de 1617 dispone en Madrid

que se ponga junto a la panadería un palo con una escarpia, y se pregone que ninguna verdulera y huevera no venda verdura ni huevos ni otro mantenimiento fuera de sus puestos, ni lo vayan a vender a la dicha panadería, so pena de ser puestos en la dicha escarpia ${ }^{24}$.

En la práctica, y a pesar de la prolija reglamentación, muchos vendedores escapaban al control. Además, las autoridades dispensaban innumerables veces licencias en atención a criterios cambiantes. En muchos casos, la extrema pobreza y necesidad constituía un argumento a favor de otorgar permiso a los miserables vendedores callejeros. Así, por ejemplo, a un manco, con mujer e hijos que sustentar, podía concedérsele un puesto para que vendiera aguardiente, mientras que a otros se les denegaba ${ }^{25}$.

Por su fama de miserables y embaucadores, los vendedores callejeros eran acusados frecuentemente de colocar género defectuoso, o incluso se les hacía responsables de casos de insalubridad y contagio. Si a mediados del siglo XVII aparecía una epidemia de tercianas en Madrid, las autoridades echaban la culpa a los melones que despachaban las revendedoras para los pobres y muchachos que no podían acceder a fruta de calidad ${ }^{26}$. Regatones y revendedores sufrían una especial desconsideración, y se les culpaba durante el siglo XVII de encarecer los precios, así como de periódicas carestías de productos, tal

19 Ibídem, vol. 2, p. 31.

20 Ibídem, vol. 3, p. 294.

21 Ibídem, vol. 4, p. 465.

22 R. Duroux, "España país tradicional de inmigración. Los auverneses de Castilla y sus fuentes", Migraciones \& Exilios: Cuadernos de la Asociación para el estudio de los exilios y migraciones ibéricos contemporáneos, 1 (2000), pp. 97-127.

23 P. López de Ayala, Rimado de Palacio, Madrid, Castalia, 1987, pp. 179-182.

24 M. Herrero, Madrid en el teatro..., p. 10.

25 M. Herrero, Oficios populares en la sociedad de Lope de Vega, Madrid, Editorial Castalia, 1977, p. 154. M. Herrero, Madrid en el teatro..., p. 11. 
y como afirma una Pragmática de 13 de septiembre de 1627 (ley IX, tít. V, libro IX de la Novísima Recopilación). Peor fama aún arrastraban los vendedores ambulantes, gente que vivía de forma itinerante, de pueblo en pueblo, muchas veces al margen de la ley. Los tenderos que regentaban pequeños comercios se quejaban continuamente de ellos; refiriéndose a la costumbre de vender por las calles aceitunas, verduras y otros productos, un tendero madrileño criticaba que ello "sólo sirve de hacerse vagamundos los que andan por dichas calles"27.

El secular rechazo a los trabajos manuales, la particular suspicacia que despertaban los comerciantes, el carácter itinerante y, en todo caso, callejero de muchos vendedores, así como la pobreza de los que se ganaban la vida con un miserable puestecillo, no fueron empero las únicas razones para comprender la mala fama de los vendedores callejeros. En muchos casos, el desdén provenía de que trataban con mercancías y productos considerados impuros o, al menos, sucios, de ínfimo status, lo que confinaba estos trabajos a colectivos considerados igualmente contaminados ${ }^{28}$ : las clases más pobres, además de emigrantes 0 minorías étnico-religiosas. Por ejemplo, solo las mujeres de extracción más baja trabajaban como mondongueras, de la misma manera que eran en gran medida emigrantes franceses los que vendían aceite y vinagre ${ }^{29}$, y asturianos los que trabajaban como aguadores ${ }^{30}$.

Con estas significaciones, no extraña que la literatura de los siglos XVI y XVII asocie el comercio callejero a la picaresca. Basta leer, por ejemplo, La vida y hechos de Estebanillo González ${ }^{31}$. En la novela picaresca, sus protagonistas se ganan la vida muchas veces revendiendo diversos productos o intercambiándolos por otros, en un comercio callejero en el que recala toda suerte de pillos y bribones. Estos se desempeñan en los más bajos escalafones de la venta callejera: son a menudo, como Estebanillo González, buhoneros, gente que vende todo tipo de mercancía menuda.

\section{EL OTRO: EMIGRANTE Y MINORÍA ÉTNICO-RELIGIOSA}

Hay que tener en cuenta que en España se dedicaron especialmente a la venta y reventa callejera los que no tenían tierras ni podían acceder a otros oficios de mayor prestigio. Caso paradigmático es el de los moriscos. Es sabido que entre ellos fueron frecuentes los oficios itinerantes: arrieros, muleros, recoveros, trajineros y todo tipo de vendedor ambulante ${ }^{32}$. Privados muchos de ellos de la posibilidad de trabajar la tierra, el transporte así como la compraventa tanto en tiendas fijas como de manera ambulante, constituyeron un salvavidas para muchas familias moriscas. Por ejemplo, en unas actas de 1598 se dice de los moriscos de Guadalajara: "Y lo peor es que con que han dado en ser tenderos, tratantes y corredores y otros oficios de comercio y abastecimiento de las ciudades y lugares"33. Efectivamente, Cuzcuz, el morisco de Amar después de la muerte, de Calderón, tiene una "tendecilla en

\section{Ibídem, p. 53.}

28 Véase el clásico de M. Douglas, Pureza y peligro. Un análisis de los conceptos de contaminación y tabú, Madrid, Siglo Veintiuno, 1973.

29 M. Herrero, Oficios populares..., p. 154.

30 J. Jiménez Mancha, Asturianos en Madrid. Los oficios de las clases populares (siglos XVI-XX), Gijón, Muséu del Pueblu d’Asturies, 2007.

31 La vida y hechos de Estebanillo González, vol. 2, Madrid, Cátedra, 1990, pp. 182-183.

32 J. Caro Baroja, Los moriscos del Reino de Granada. Ensayo de historia social, Madrid, Istmo, 2000, p. 213.

33 M. F. Fernández Chaves y R. M. Pérez García, En los márgenes de la ciudad de Dios. Moriscos en Sevilla, Valencia, Publicacions de la Universitat de València, Editorial Universidad de Granada, Servicio de Publicaciones de la Universidad de Zaragoza, 2009, p. 305. 
Bevarrambla" en la que vende de todo un poco, desde "aceite, vinagre e higos", hasta "hostios para cerrar cartas"34. Los moriscos controlaban en gran medida tanto la venta de cierto género, como su transporte, con recuas de mulos. Las autoridades no vieron siempre con buenos ojos este trajín, dado que así escapaban a su control ${ }^{35}$. En la literatura del Barroco, muchos de estos oficios del camino eran desconsiderados, acaso porque latía la idea de que en ellos recalaron muchos castellanos nuevos. Así son abundantísimas las sátiras hacia mozos de mulas, arrieros y buhoneros. Si los dos primeros eran tachados de deslenguados, todos tenían fama de embaucadores.

Entre los oficios considerados típicos de moriscos, destacan varios dedicados a la producción y venta en la calle. Moriscas eran muchas de las buñoleras, y moriscos eran también algunos de los que vendían esteras de esparto, agua, o comidas típicas de su régimen alimentario, como higos y pasas. De esto último da cuenta un texto de Vélez de Guevara, que acaba así la enumeración de los oficios moriscos: "Aquel calvo, por las calles I higos y pasas vendía; / todos son canalla infame"36. El morisco de Las ferias de Madrid de Lope, también vende "muy buenos higos / y un agua como la nieve"37. En el oficio de aguador, coexistían los moriscos con emigrantes asturianos, gallegos y franceses, todos los cuales acudían a Madrid, Andalucía y a otros lugares para ganarse la vida. "Franceses que pregonáis / aguardiente y letuario ${ }^{38 ", ~ e s c r i b e ~ L o p e ~ d e ~ V e g a ~}{ }^{39}$.

En ocasiones, algunos de estos trabajos eran desempeñados por extranjeros en toda Europa. Es el caso de los buhoneros, que eran frecuentemente emigrantes de las zonas montañosas y periféricas. Así, en ciertas ciudades alemanas, der Italiener (el italiano) era la forma habitual para referirse a ciertos comerciantes, y en Dinamarca el buhonero era tildado de scot (escocés), de la misma manera que en España esta figura se correspondía con la del francés, el gabacho ${ }^{40}$. La emigración francesa, especialmente de la Auvernia, se remonta a la Edad Media. Hombres, y solo hombres, acudieron a tierras castellanas y aragonesas primero por los lazos religiosos y feudales, y posteriormente, ya a partir del siglo XV, por la diferencia salarial. Frente a otros países, los salarios en España eran altos, al menos hasta 1630 aproximadamente; por otra parte, en España se ofrecían tierras libres; y finalmente, el desdén por los trabajos manuales entre los españoles generaba puestos libres especialmente en aquellos oficios menos considerados ${ }^{41}$. En el siglo XVII, miles de franceses trabajaban en España, muchos de ellos dedicados a la venta ambulante, abasteciéndose mediante un sistema de comercios familiares que ha sido estudiado por Laurence Fontaine ${ }^{42}$. Aunque muchos de los buhoneros hacían el viaje de ida y vuelta en poco tiempo, otros se establecieron en España, y acabaron ejerciendo de caldereros, panaderos, merceros, vendedores de aceite y tenderos de todo tipo. Así, durante mucho tiempo, estos oficios fueron considerados típicos de franceses, especialmente el de tahonero, de lo que tenemos muchos ejemplos en Madrid o Andalucía ${ }^{43}$. En el siglo XVII, varias ciudades como Toledo, Granada y Córdoba se alzaron contra la pretendida expulsión

34 P. Calderón de la Barca, Obras completas. Dramas, vol. 1, Madrid, Aguilar, 1966, p. 353.

35 J. Caro Baroja, Los moriscos..., p. 213.

36 L. Vélez de Guevara, Más pesa el rey que la sangre y Reinar después de morir, Madrid, Akal, 2002, p. 112.

37 L. de Vega, Las ferias de Madrid y La Vitoria de la Honra, Valencia, Estudios de Hispanófila, 1977, p. 57.

38 Especie de mermelada.

39 L. de Vega, El acero de Madrid, Madrid, Castalia, 2000, p, 132.

40 L. Fontaine, History of Pedlars..., p. 11.

41 B. Bennassar, La España del Siglo de Oro, Madrid, RBA, 2006, p. 101.

42 L. Fontaine, History of Pedlars...

43 R. Duroux, "España país tradicional...", p. 100. 
de los franceses, habida cuenta de que en algunos sitios una gran parte de los panaderos eran galos y en otros aguadores, y ambos se consideraban esenciales ${ }^{44}$.

En la literatura del siglo XVII el trotamundos y el que se gana la vida en la calle es frecuentemente un personaje estereotipado llamado Juan Francés, Gascón, Pierre o simplemente gabacho. La literatura pinta como franceses a afiladores, cerrajeros, aguadores, castradores, titiriteros, buhoneros, o simplemente pordioseros que vagan por los caminos vendiendo rosarios $u$ ofreciendo diferentes servicios ${ }^{45}$. Todos ellos eran oficios itinerantes. Pero sobre todo es el buhonero, el arquetipo más frecuente del francés, al que despectivamente se le llama a veces "gabacho", como recrea Lope en Las ferias de Madrid $^{46}$. El Diccionario de Autoridades no deja lugar a dudas sobre el sentido del término:

Gabacho. F. m. Soez, asqueroso, sucio, puerco y ruin. Es voz de desprecio con que se moteja à los naturales de los Pueblos que están à las faldas de los Pyreneos entre el rio llamado Gaba, porque en ciertos tiempos del año vienen al Reino de Aragón, y otras partes, donde se ocupan y exercitan en los ministerios mas baxos y humildes ${ }^{47}$.

Así aparece en obras de Lope de Vega (El abanillo), Castillo Solórzano (La niña de los embustes) o Tirso de Molina (Quien no cae, no se levanta; Por el sótano y el torno). Considerando su frecuencia en el teatro, parece que el buhonero francés constituía un personaje estereotípico, conocido por el público. En el entremés de Navarrete y Ribera, La buscona, de 1640, el francés vende "punta y tranzadera". Abraham Madroñal ${ }^{48}$ cita otros entremeses en que aparece un estereotipado Juan Francés como buhonero, alguno de elocuente título: Comprar peines, gabacho, de Tirso de Molina. No pocas veces pregona su mercancía menuda por las calles. En la comedia de Moreto Las travesuras de Pantoja, de 1662 , se disfraza uno de "buhonero gabacho, con una caja":

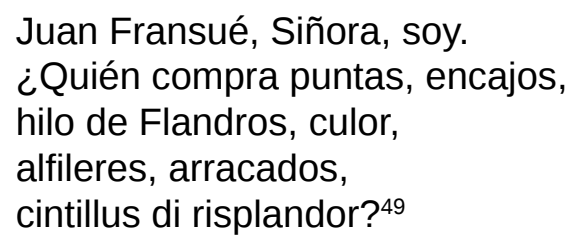

Además de hablar una jerga singular, con mezcla de italiano y francés, el buhonero francés es tildado a veces de cómico, borrachín. No podía faltar la sátira contra el vendedor ambulante francés en Quevedo, quien retrata a tres de estos tipos; un afilador "con un carretoncillo de amolar tijeras y cuchillos por babador", un vendedor de ratoneras, y un buhonero "con un cajón de peines y alfileres" 50 . Como ocurría con los arrieros y trajineros moriscos, también los buhoneros franceses levantaban sospechas: fue creencia que traficaban en realidad con oro. En Los cigarrales de Toledo, Tirso habla de "los próvidos franceses que, vendiendo hilo portugués en nuestra patria y amolando tijeras, sin ser

44 L. Fontaine, History of Pedlars..., p. 25.

45 M. Herrero, Ideas de los españoles del siglo XVII, Madrid, Editorial Gredos, 1966, pp. 385-416.

46 L. de Vega, Las ferias de Madrid..., p. 27.

47 Diccionario de Autoridades, vol. 2, Madrid, Gredos, 1990, voz 'gabacho'.

48 A. Madroñal, "Juan Francés, vida entremesil de un personaje literario", en M. C. García de Enterría y A. Cordón Mesa (ed. lit.), Actas del IV Congreso Internacional de la Asociación Internacional Siglo de Oro (AISO), vol. 2, Alcalá de Henares, 1998, p. 967.

49 A. Moreto, Comedias escogidas, Madrid, BAE XXXIX, Ediciones Atlas, 1950, p. 397.

50 F. de Quevedo, La hora de todos y La fortuna con seso, Madrid, Castalia, 2009, p. 246. 
alquimistas convierten el yerro en oro"51. Parece que algunos de los auverneses que pregonaban por las calles "hilo de Flandes", compraban en realidad oro. En todo caso, fuera o no lo que consideraríamos hoy una leyenda urbana, el hecho es que sobre los buhoneros siguió pesando, como en la Edad Media, su fama de embaucadores, aunque no eran los únicos sobre los que caía tal estigma.

\section{OFICIO DE GITANOS}

Es sabido que los gitanos, prácticamente desde su llegada a España en el siglo $\mathrm{XV}$, se han servido de la venta ambulante para sobrevivir, habida cuenta de su carácter nómada e itinerante. Es significativo lo pronto que los gitanos cristalizaron como arquetipo literario, exótico y costumbrista. El Auto de las gitanas de Gil Vicente, representado en torno al año 1525, retrata a las gitanas con algunos de los rasgos que se convertirán en prototípicos: piden limosna, echan la buenaventura, cantan, bailan y provocan las risas con su lenguaje ceceante ${ }^{52}$. Junto a esta mirada casi curiosa, que les tomó como extraños exóticos, prevaleció la visión estigmatizadora que vio en los gitanos gente vagabunda, ladrona, embaucadora, pedigüeña, peligrosa en suma. Son paradigmáticas las palabras que les dedica Covarrubias en su Tesoro de la Lengua Castellana de 1611. Después de hacerse eco de la creencia según la cual, los gitanos (cuasi egitano) provenían de Egipto, y que "por no haber querido albergar al niño peregrino y a su Madre y a José, les cayó la maldición de que ellos y sus descendientes fuesen peregrinos por el mundo, sin tener asiento ni morada permanente haber traicionado a la Virgen"53, Covarrubias les dedica los oprobios habituales en la época:

Esta es una gente perdida y vagabunda, inquieta, engañadora, embustidora [...]. Fuera de ser ladrones manifiestos, que roban en el campo y en poblado, de algunos dellos se puede presumir que son espías [...]. En España los castigan severamente, y echan a los hombres a galeras, si no se arraigan y avecinan en alguna parte; las mujeres son grandes ladronas y embustidoras, que dicen la buenaventura por las rayas de las manos [...]. Harto está dicho desta ruin gente ${ }^{54}$.

En gran medida, pesó la mala fama de sus oficios itinerantes y callejeros, cuando no su asociación a la mendicidad y al robo. El estigma del vendedor gitano estaba ya consolidado en el siglo XVI. Un extracto de los Coloquios de Palatino y Pinciano ${ }^{55}$, escrito por Arce de Otálora a mediados del siglo XVI, lo deja claro:

Pinciano: Si queréis que os haga dar aquí en esta feria un pregón, veremos si hay aquí quien os ponga en precio.

Palatino: Si sois vos el vendedor, ninguno me osará comprar, pensando que sois gitano.

Entre sus trabajos predilectos destacaron siempre los dedicados al trato de bestias, la herrería ambulante y la venta de diversos productos, trabajos que despertaban las sospechas de las autoridades. En la Pragmática de 1499 de los Reyes Católicos, en la cual se les obliga a abandonar el nomadismo y asentarse en lugares fijos, se dictamina

51 Tirso de Molina, Cigarrales de Toledo, Madrid, Luis Sánchez, 1624, p. 245.

52 G. Vicente, Teatro castellano, Barcelona, Crítica, 1996, pp. 263-273.

53 S. de Covarrubias Orozco, Tesoro de la Lengua Castellana o Española, Madrid, Castalia, 1995, p. 590.

54 Ibídem, pp. 590-591.

55 J. de Arce de Otálora, Coloquios de Palatino y Pinciano, vol. 1, Madrid, Fundación José Antonio de Castro, Turner, 1995, p. 599. 
que los egipcianos y caldereros extranjeros durante los sesenta días siguientes al pregón, tomen asiento en los lugares y sirvan a señores que les den lo que hubiera menester y no vaguen juntos por reinos o que al cabo de esos sesenta días salgan de España, so pena de cien azotes y destierro perpetuo la primera vez, y que les corten las orejas y los tornen a desterrar a la segunda vez que fueren hallados ${ }^{56}$.

No extraña que la legislación aluda a "egipcianos" y "caldereros extranjeros", ya que el trabajo del metal y, muy particularmente, el de calderero fue efectivamente consustancial a gran parte de los gitanos de toda Europa, como ha demostrado Clebert ${ }^{57}$. La legislación antigitana, promulgada a partir del siglo XV, censura muchas veces que los gitanos se dediquen a los oficios de calderero, herrero, esquilador o chalán, abogando por su sedentarización, como pretendía un bando de Madrid, fechado en 1609:

Habiendo entendido que en esta Corte y fuera de ella andan gran número de jitanos y de jitanas vagamundos, que no se ocupan en oficios, de que se siguen muy grandes daños e inconvenientes, dijeron que mandaban y mandaron que los dichos jitanos y jitanas se ocupen en oficios tocantes a la labranza y cultura de la tierra, y no puedan ser trajineros, ni hacer oficios de mercaderes ni de ningún género de mercancía, ni tengan tiendas de mercancías ni de otras $\operatorname{cosas}^{58}$.

En España, los herreros gitanos sufrieron siempre el recelo de la población mayoritaria, entre otras razones porque el oficio se vinculó a actividades delictivas, especialmente a lo largo de los siglos XVI y XVII. Un villancico, cantado en Lucena durante la Navidad de 1694, recoge el estereotipo del gitano herrador ladrón ${ }^{59}$ :

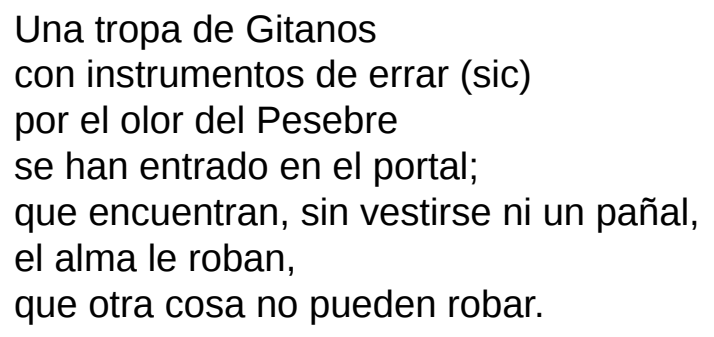

Si la compraventa de caballerías se asoció al cuatrerismo y a la estafa, la herrería se vinculó a la fabricación de útiles con fines delictivos. Sancho de Moncada considera en 1619 que los gitanos "son gente ociosa, vagabunda, inútil a los Reynos, sin comercio, ocupación, ni oficio alguno; y si alguno tiene es hacer ganzúas, y garabatos para su profesión"60. De la misma opinión es Juan Quiñones de Benavente, que en su Discurso contra los gitanos, escrito en 1631, los compara con los moriscos y los considera aún peor al no trabajar la tierra: "Si en algo se ocupan, es en hacer barrenas, por ser una especie de ganzúas, y aun por disimularlas, las muchas que entre las barrenas hacen" ${ }^{61}$. El propio Cervantes da crédito a esta opinión. En El coloquio de los perros, Berganza, uno de los canes protagonistas,

56 F. de Sales Mayo, El gitanismo, historia, costumbres y dialecto de los gitanos, Madrid, Librería de Victoriano Suárez, 1870, p. 24.

57 J. P. Clebert, Los gitanos, Barcelona, Aymá editora, 1965, pp. 128-131.

58 M. Herrero, Madrid en el teatro..., p. 645.

59 C. Bravo-Villasante, Villancicos del siglo XVII y XVIII, Madrid, Editorial Magisterio, 1978, p. 60.

60 S. Moncada, Restauración política de España y deseos públicos, Madrid, Juan de Zúñiga, 1746, p. 131.

61 J. Quiñones de Benaventes, "Discurso sobre los gitanos", en F. Grande, Memoria del Flamenco, Madrid, Alianza Editorial, 1999, p 534. 
menciona - al describir su estancia con un grupo de gitanos cerca de Granada-, que estos se emplean "por dar color a su ociosidad, en labrar cosas de hierro; haciendo instrumentos con que facilitan sus hurtos; y así, los verás siempre traer a vender por las calles tenazas, barrenas, martillos, y ellas, trébedes y badiles"62.

Efectivamente, los herreros gitanos iban de pueblo en pueblo vendiendo y reparando todo tipo de piezas, desde aperos de labranza, hasta herraduras, en cuadrillas itinerantes como las que describe Jerónimo de Alcalá, en la segunda parte de Alonso, mozo de muchos amos, de 1626. La literatura de la época se hizo eco muchas veces del tópico del gitano cuatrero o herrero ladrón, que trafica con material robado, como recrea Cervantes en El coloquio de los perros ${ }^{63}$ o Lope de Vega ${ }^{64}$. En parte, el oficio de herreros itinerantes deriva de la arcaica asociación de los calés con el trabajo de los metales. Pero más específicamente, la herrería resultaba lógica dado el abastecimiento de herraduras que necesitaban como tratantes de bestias. Hay que recordar que los gitanos no solo vendían y compraban caballos, mulos y burros, sino que también ejercían como albéitares. Así, pues, vagabundeo, chalaneo, herrería, gitanos, engaños y robos quedaron vinculados desde al menos el siglo XVI. Otros oficios, típicos de gitanos, como el de trasquilador o ventero, también se deducían de esta forma de vida itinerante, y fueron objeto de similares estigmas. En algunos lugares, especialmente del sur peninsular, dichos trabajos fueron ocupados además por otros morenos (moriscos, negros, mulatos), hasta el punto de que aún en 1788, escribía Antonio de Capmany: "Herrería y trasquila, las carnicerías y las posadas, ¿no corren a manos de mulatos y gitanos?"65.

\section{BUHONEROS, CHARLATANES, CIEGOS Y OTROS VAGABUNDOS}

En la plaza, en el mercado o en la feria, el vendedor callejero se ganó la vida conviviendo con otros sujetos que también tenían en los lugares públicos su lugar de trabajo. Muchos de ellos vivían de los más variados espectáculos, en una época en que la plaza no constituía solo un lugar de transacciones económicas, sino también de paseo y esparcimiento $^{66}$. El estilo de vida de los vendedores callejeros, y muy particularmente de los ambulantes, quedó asociado a tipos como los antiguos juglares, titiriteros, decidores de buenaventura y charlatanes. Al menos desde la Edad Media, muchos vendedores callejeros eran subsumidos bajo la categoría del pícaro charlatán. Entre los diferentes oficios con que Estebanillo González se gana la vida en Sevilla engañando a quien se pone a tiro, está el de montambanco: "Puse mi mesa de montambanco y, ayudándome del oficio de charlatán, ensalzaba mis drogas y encarecía la cura y vendía caro"67. El montambanco es equivalente al "salta en banca" que recoge Covarrubias en su Tesoro de la lengua castellana o española: "el chocarrero o charlatán, que en las plazas se sube en las bancas y de allí hace sus pláticas para vender las medicinas y drogas que trae"68.

También el buhonero es frecuentemente tildado de charlatán. La naturaleza del buhonero la retrata bien Tirso de Molina en Quien no cae, no se levanta, de 1623. En la caja

62 M. de Cervantes, Novelas ejemplares, vol. 2, Madrid, Cátedra, 2007, p. 348.

63 Ibídem, p. 323.

64 L. de Vega, Obras escogidas, vol. 1, Madrid, Aguilar, 1966, p. 1408.

65 Semanario Erudito que comprende varias obras inéditas, críticas, morales, instructivas, políticas, históricas, satíricas y jocosas de nuestros mejores autores, vol. 9, Madrid, Blas Román, 1788, p. 197.

66 Como en su día demostraron M. Bajtin (La cultura popular en la Edad Media y en el Renacimiento. El contexto de François Rabelais, Madrid, Alianza Universidad, 1995) y P. Burke (La cultura popular en la Europa Moderna, Barcelona, Altaya, 1977).

67 La vida y hechos...,vol. 1, pp. 207-208.

68 S. de Covarrubias Orozco, Tesoro de la Lengua..., pp. 161. 
de este se esconde no solo todo tipo de menudencia para el aseo y la belleza, sino también brebajes y ungüentos como los que traían los charlatanes: "sangre de drago en palillos, I dijes de alquimia y acero, /quinta esencia de romero"69.

El charlatán y el buhonero comparten espacio, intención y escala social con otros sujetos callejeros no menos devaluados, como los ciegos. En su Plaza universal de todas ciencias y artes, de 1615, Suárez de Figueroa dedica un capítulo a "los formadores de espectáculos en general, y en especial de los charlatanes, y ciegos". Después de tildar a los charlatanes de "gente perdida, ociosa, vagabunda, de vida desconcertada, de mal ejemplo,

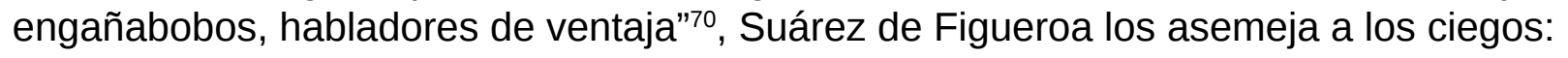

El oficio de estos [los charlatanes] parece quisieron usurpar en España los ciegos, república bien semejante a la de los otros, salvo que su mercaduría termina en repertorios, o coplas, en que se refieren casos monstruosos acontecidos en lejanas partes ${ }^{71}$.

Es el ciego un tipo de charlatán, y por ello igualmente "miserable género de hombres"72. La particular actuación del ciego queda clara por la descripción de Suárez de Figueroa, quien reconoce el gusto que el público experimenta al oírle:

En cierto modo deleita grandemente oír la pomposa arenga de un ciego que, subido en una mesa, acompañado, o solo, procura con su guitarra y mala voz captar la benevolencia del auditorio, tras quien propone el caso de las tales coplas, haciendo de ellas una sucinta relación, adornada de algunas inmoralidades, o ejemplos ${ }^{73}$.

Ciegos y charlatanes comparten el hecho de que ambos tienen en la voz su principal recurso para vender una mercancía, que Suárez de Figueroa juzga fantástica. En la calle se mezclan con "los que llaman Bolatines", con "extranjeros manejadores de títeres" o con los que ofrecen ver, previo pago, algún prodigioso animal ${ }^{74}$. Suárez de Figueroa censura a todos, pues los considera vagabundos; "andan toda la vida baldíos, y como Gitanos de una tierra a otra"75. Una y otra vez, el status de los vendedores callejeros remite a los mismos estigmas: pobreza, charlatanería, engaño, vileza del trabajo y aun vagabundeo, picaresca. El pregón es su forma de expresión, la plaza su patria, y el mercado, la feria y la fiesta sus tiempos primordiales.

\section{LA PLAZA, EL PREGÓN Y LA CULTURA CÓMICA POPULAR}

Debemos a M. Bajtin algunas de las reflexiones más lúcidas sobre los pregones, al contextualizarlos como una expresión de la cultura cómica popular. Para Bajtin, la plaza pública es el lugar de lo extraoficial, en el que "todas las expresiones orales (desde las interpretaciones a voz en grito a los espectáculos organizados) tenían algo en común, y estaban basados en el mismo ambiente de libertad, franqueza y familiaridad"76. Si la plaza es el territorio de la cultura popular, su tiempo predilecto es el de la fiesta y, en gran medida,

69 Tirso de Molina (Gabriel Téllez), Obras dramáticas completas, vol. 3, Madrid, Aguilar, 1968, p. 850.

70 C. Suárez de Figueroa, Plaza universal de todas ciencias y artes, parte traducida del Toscano, y parte compuesta por el doctor... Madrid, Luis Sánchez, 1615, f. 325r.

71 Ibídem

72 Ibídem.

73 Ibídem.

74 Ibídem, f. 235v.

75 Ibídem, f. 326r.

76 M. Bajtin, La cultura popular..., p. 139. 
el de la feria. En la plaza, el trato familiar y libre permitía que los vendedores callejeros y los clientes se despojaran de las convenciones del decoro presentes en el día a día. Las reglas de urbanidad seguían rigiendo el trato en las casas, en las iglesias, en los tribunales y, en general, en todo espacio y tiempo oficial; pero en los mercados y ferias, desparramados por plazas y calles, el pueblo llevaba la voz cantante, y lo hacía con un lenguaje deliberadamente apartado y opuesto al lenguaje oficial del establishment: un argot de sabor carnavalesco.

Los géneros cultos se inspiraron en ese lenguaje frecuentemente, tanto en sus creaciones literarias (como hace Rabelais o, en nuestro contexto, Cervantes), como en sus formas dramatúrgicas, rituales y festivas, como eran las fiestas de locos o del asno. En el Pantagruel de Rabelais ${ }^{77}$, Panurgo convierte a su prisionero, el rey Anarco, en pregonero de salsa verde, lo que constituye toda una degradación simbólica, aumentada grotescamente al hacerle casar con una vieja ramera que, para colmo, le muele a palos.

Para comprender la naturaleza del pregón en el contexto de la cultura cómica popular, hay que ponerlo en relación con otros géneros y otras costumbres de la plaza pública. El anónimo autor de La vida y hechos de Estebanillo González hace desembarcar al protagonista en Nápoles, donde este se entretiene "en oír comedias españolas y italianas", así como "en ver en el Largo del Castillo ${ }^{78}$ la variedad de montambancos y charlatanes, la poca venta de sus badulaques y la grande multitud de sus arengadas prosas y oyentes noveleros" ${ }^{\prime \prime}$. La plaza pública constituía el contexto principal de entretenimiento, pero también era el lugar cotidiano de trabajo de las clases populares, especialmente en el día de mercado. En gran medida, era un lugar ambivalente y polifacético. Por un lado, en el centro neurálgico de la villa o ciudad estaba representado también el poder eclesiástico y municipal, a través de la iglesia y el ayuntamiento. Por otro, el mercado solía celebrarse en el centro de la localidad, la plaza, lugar simbólico donde lo mismo se vendía y compraba, que se festejaba. Así, pues, concurrían en un mismo espacio el poder eclesiástico y civil, y las clases populares, entre las que se mezclaban saltimbanquis, ciegos, prestidigitadores, ladrones y todo aquel que quisiera ganarse el pan, solicitando los favores del público.

Como género eminentemente popular, el pregón destila a veces un gusto por lo que Bajtin llamó "realismo grotesco", una lógica y aun una estética que distorsiona y magnifica lo carnal, enfatizando por igual cuanto hay de vil y de ensoñador en la carne, en el queso, en el vino. En ese sentido, el oficio del vendedor de comestibles es ambivalente, dado que lo que ofrece es para la satisfacción del cuerpo, pero por ello mismo, su presencia evoca el, nunca extirpado del todo, sueño de la superabundancia y el placer. En una época en que el hambre no era precisamente la más irrelevante de las cuitas populares, la imagen de descomunales salchichas, morcillas y torreznos forman parte de una estética carnavalesca, que lo mismo exaltaba que degradaba lo carnal y material. La hipertrofia de lo carnal es, en fin, un rasgo de la cultura cómica popular que lo mismo puede verse en ciertas fiestas y diversiones populares de sabor carnavalesco ${ }^{80}$, que en las bromas y el ánimo chisposo que acompaña a las matanzas, o en ciertos géneros literarios, entre los que los pregones de ciertos alimentos no son los menos frecuentes.

El pregón que exalta la superabundancia de objetos y víveres, y muy especialmente aquellos vinculados a la carne y la sangre, supone no solo el envés de la cotidiana carestía, sino también un grito de resistencia simbólica contra el pecado de gula y aun contra cualquier

77 F. Rabelais, Pantagruel, Madrid, Cátedra, 2003, p. 312.

78 Era el lugar donde se daban cita charlatanes, prostitutas, valientes y diversos espectáculos callejeros. Véase F. Nicolini, Aspetti della vita italo-spagnuola nel Cinque e Seicento, Nápoles, Alfredo Guida, 1934 , p. 333.

79 La vida y hechos de Estebanillo..., vol. 2, p. 266.

80 A. del Campo, "El culo en el cancionero de tradición popular. Realismo grotesco, escatología y obscenidad en contextos festivos liminares", Revista de Dialectología y Tradiciones Populares, 68, 2 (2013), pp. 489-516. 
precepto censurador de la libertad festiva, el derroche y el placer. Hay que tener en cuenta que la crítica a la glotonería constituyó, desde antiguo, un tópico extendidísimo en los escritos moralistas, especialmente religiosos. A mediados del siglo XVII, Juan de Zabaleta critica en El día de fiesta por la mañana la glotonería de los que oyen misa mientras piensan "divertidamente en comer superfluidades"81. La sentencia es típica: "tiene el demonio preso al glotón con el bocado"82.

En términos opuestos (ensalzando todo lo pantagruélico) se manifiestan las clases bajas, especialmente los rústicos, tal y como son retratados en la literatura, desde los pastores de nuestros primeros dramaturgos (Juan del Encina o Lucas Fernández) hasta el más célebre de nuestros glotones literarios: Sancho Panza. El pregón es parte esencial de toda fiesta en que se celebra la utopía de un paraíso en que no falta de nada. Más que comer, atiborrarse; esta ha sido una de las características aún vigentes en la fiesta popular. La literatura lo recreó mil veces. "Fiesta donde no comemos / es vigilia, que no es fiesta", dice uno de los personajes de Los motes, una mojiganga carnavalesca escrita por Manuel León Marchante en $1667^{83}$.

En ese sentido cabe interpretar las frecuentes alusiones que hacen nuestros escritores del Barroco a esa abundancia en la fiesta y aun en el mercado. En La moza de cántaro, Lope de Vega canta los mil y un productos que se vendían en las calles de Madrid: "letuarios y conservas; / mil figurillas de azúcar, / flores, rosarios, rosetas, / rosquillas y mazapanes, / aguardientes y canela [...]" ¿44. ¿No hay en la compulsiva enumeración una intención de transmitir la ensoñadora imagen de opulencia y aun de caos chorreante de comidas y objetos? ¿No está presente, en el fondo, la utopía del banquete universal, donde todos son olores y sabores, y se satisface precisamente la pasión por poseer los objetos menos instrumentales y caprichosos?

\section{LA PLACERA: UN TIPO CARNAVALESCO}

La plaza constituía, por lo tanto, el lugar de trabajo principal para muchas personas, pero la venta de alimentos estuvo durante mucho tiempo en manos de mujeres; las llamadas placeras. Hay que tener en cuenta que, durante siglos, estuvo prohibido que los propios hortelanos vendieran sus productos en la propia finca. En el siglo XVII la venta de hortalizas la llevaban a cabo verduleras que contaban con un título otorgado en escritura por los hortelanos productores. Dado que la reventa estaba prohibida, las verduleras solían ser las hijas y esposas de los que ostentaban fincas en propiedad o en arrendamiento, pero también fue frecuente que los labradores contratasen ex profeso a "criadas" para que a diario vendiesen la mercancía en la plaza.

Unas y otras eran puestas en la picota, como queda claro por los testimonios de los agentes de justicia de la época. Un observador de mediados del siglo XVII se hace eco del sinfín de productos que estas vendían, desde limones a avellanas, requesón, leche o rosquillas $^{85}$. El cronista critica no solo que las mujeres se dediquen a la reventa, sino que se sitúen con sus puestecillos portátiles junto a tabernas y esquinas, alrededor de los cuales se daban cita los estratos menos decentes de la sociedad:

81 J. de Zabaleta, El día de fiesta por la mañana y por la tarde, Madrid, Editorial Castalia, 1983, p. 195.

82 Ibídem, pp. 196-197.

83 C. Buezo (ed.), Mojigangas dramáticas (siglos XVII y XVIII), Madrid, Cátedra, 2005, p. 130.

84 M. Herrero, Oficios populares..., pp. 136-137.

85 M. Herrero, Madrid en el teatro..., p. 52. 
Otras tratan de mondongo blanco y negro y callos, y no hay taberna ni esquina donde no haya a la mañana y la tarde una y dos ollas de esto, cercadas de pícaras y pícaros, vagamundas de mal vivir $[\ldots]^{86}$.

La referencia a los mondongos y los callos es maliciosa, por cuanto la autoridad quiere dar a entender que tan viles son los productos como la gentuza que los vende. Otros testimonios de la época confirman la profusión de mujeres a cargo de estos puestecillos callejeros. En el relato que de su viaje hace un embajador marroquí entre 1690 y 1691, se describe el ambiente de la plaza mayor de Madrid en el horario de mercado. Y son mujeres las que, en medio de la plaza, venden el pan, las legumbres, la fruta y toda clase de carne ${ }^{87}$.

La literatura barroca recreó muchas veces la mala fama de las placeras. Cervantes hace decir a Sancho que "es fama en este pueblo que no hay gente más mala que las placeras, porque todas son desvergonzadas, desalmadas y atrevidas, y yo así lo creo, por las que he visto en otros pueblos"88. Y en El juez de los divorcios, un ganapán se arrepiente de haber quitado a su mujer de la mala vida para meterla a placera:

Ha salido tan soberbia y de tan mala condición, que nadie llega a su tabla con quien no riña, ora sobre el peso falto, ora sobre que le llegan a la fruta, y a dos por tres les da con una pesa en la cabeza o adonde topa, y los deshonra hasta la cuarta generación, sin tener hora de paz con todas sus vecinas ya parleras ${ }^{89}$.

Fue proverbial, efectivamente, su tendencia a las riñas y, en general, a las trifulcas con otras placeras, y aun con los clientes, tópico que fue frecuente en los entremeses del siglo XVII. Así, por ejemplo, en el Entremés famoso de las vendederas en la puerta del Rastro, Gil de Armesto y Castro ${ }^{90}$ hace reñir a una vendedora de morcillas y a otra que despacha manos de carnero y cuajares, es decir, el estómago del animal. El Rastro era una plazoleta donde se compraban y vendían los despojos de los animales sacrificados en el matadero. Hasta allí acudía la gente para comprar manos y pies de cordero, mondongos, lengua, cabeza, gordura y todo desperdicio cárnico. Si las verduleras tenían fama de deslenguadas, las que trabajaban en el Rastro, entre despojos, sangre y no poca carne putrefacta, no debían pertenecer precisamente a las clases acomodadas. Así, no extraña que Armesto y Castro $^{91}$ les haga entonar pregones con desparpajo e insolencia:

Morcillas vendo famosas,

[...] Venid, llegad, bribones,

que en no siendo gorrones,

la sangre de un rocín

os sabe a francolín,

y las sucias cosillas,

decís que son especia en mis morcillas.

Sin duda, las mondongueras y otras vendedoras de vísceras, con su lenguaje soez y su talante desenfadado cuando no claramente agresivo, son representantes de la cultura cómica popular que veía en lo grotesco y lo carnal uno de sus leitmotivs principales. Por eso,

86 Ibídem

87 J. García Mercadal, Viajes de extranjeros..., vol. 4, pp. 314-315.

88 M. de Cervantes, Obras completas, vol. 1, Madrid, Aguilar, 2003, p. 510.

89 Ibídem, vol. 2, p. 907.

90 G. de Armesto y Castro, Verdores del Parnaso, en diferentes entremeses, vayles, y Mogiganga, escritos por..., Pamplona, Juan Picón, Impressor del Reyno, 1697, p. 70.

91 Ibídem, p. 71. 
en el entremés en cuestión, la mujer que vende vísceras no dudará en zurrar a algún cliente con la morcilla o con la mano de carnero, recurso cómico frecuente en los entremeses, y que sugiere la caracterización carnavalesca de las placeras en el siglo XVII.

La trifulca verbal entre vendedores callejeros se convirtió en una escena repetida. Quiñones de Benavente pone a pelearse en el Baile del Alfiler, a una vendedora de chicharrones, otro de naranjas y un sillero. Los tres vendedores acaban enzarzándose en una disputa, en la que no faltan las pullas; la vendedora de chicharrones llama al sillero "zurce-sillas" y "quema-astillas" y este la trata de "tuesta-puercos" y "pringona" ${ }^{2}$. Socarronería, ingenio y chispa deslenguada son los rasgos de los vendedores callejeros. Esos mismos códigos de expresión son los que dan pie a Francisco Santos a elaborar un divertido pasaje en su obra La verdad en el potro, de 1671. Un aguador que vende agua y anís por dos maravedís, pregona alegremente en tiempo de verano: "iQué fresca que viene la putona, y qué fresca"93. Al pasar por su lado "una mujer de estas que dejan entretenido al marido y ellas van a lo mismo"94 se siente aludida y arremete contra el aguador, lo que da lugar a una violenta trifulca.

El estereotipo de la placera apicarada pervivirá durante siglos, como puede verse en los sainetes del siglo XVIII, en los cuales aún es usual presentar a castañeras y otras vendedoras que compiten entre sí y se fustigan con pullas y sarcasmos. Puede decirse que la placera, en tanto mujer deslenguada, soberbia y de fácil arrebato, es antecedente del tipo folclórico de la castañera y otras vendedoras majas del siglo XVIII. Y aun de toda una estética y expresividad que en gran medida ha perdurado hasta nuestros días. Todavía en la década de los 30 del siglo pasado, Walter Starkie ${ }^{95}$ nota que en España las mujeres no suelen llegar a las manos cuando pelean, pero son maestras en batallar con insultos e injurias. Es tópico que vemos repetido una y otra vez en el siglo XVII, como queda claro en Entremés de los Mirones de la Corte, de Salas Barbadillo:

Una [de las repúblicas] es la de las mujeres placeras, comúnmente llamadas regatonas, a quien, sin ofensa de su decoro, llamo república libre; éstas, pues, senadores de la insolencia y magistrados del licencioso lenguaje, me entretienen cuando sobre pequeños intereses dan la batalla ${ }^{96}$.

Comparten las placeras con el resto de vendedores y comerciantes el estereotipo de estafadores y mentirosos, lo que también aparece en ese mismo entremés de Salas Barbadillo: "Ellas son tales, que engañan a los despenseros, sucesores de Judas"97.

Finalmente, los agentes de justicia criticaban en el siglo XVII que muchas de las mozas que vendían "limas, rosquillas y otras golosinas" durante los paseos y fiestas públicas de Madrid, ejercían también de celestinas; "se valen de estas mujeres los hombres para enviar recados a los coches y solicitar la conversación y lo que les parece"98. He ahí la doble

92 E. Cotarelo y Mori, Colección de Entremeses, Loas, Bailes, Jácaras y Mojigangas desde fines del siglo XVI á mediados del XVIII, vol. 2, Madrid, Lasa Editorial Bailly/Bailliére, 1911, p. 649.

93 F. Santos, El no importa de España y La verdad en el potro, Londres, Tamesis Books Limited, 1973, p. 121.

94 Ibídem, p. 121.

95 W. Starkie, 1944, Don Gitano. Aventuras de un irlandés con su violín en Marruecos, Andalucía y en La Mancha, Barcelona, Ediciones Pal-las, p. 140.

96 M. Herrero, Madrid en el teatro..., p. 8.

97 Ibídem

98 M. Herrero, Oficios populares..., p. 138. 
consideración de lo carnal, que relaciona lo sexual con la abundancia de alimentos, y más típicamente con todo lo que concierne a los productos de la carne y la sangre (la morcilla, las vísceras, etc.). La placera, es, en fin, un oficio inapropiado para las damas decentes. Es más, durante años se consideraba que el carácter licencioso, incluso pendenciero, de las placeras no era propicio para las jóvenes solteras. De hecho, desde 1610 y durante décadas, las autoridades de Madrid limitaron el oficio a las mujeres casadas y a las mayores de cuarenta años, prohibiéndose que las jóvenes solteras vendieran fruta y otros comestibles en las plazas y calles, so pena de cien azotes. Este precepto era, sin embargo, de difícil cumplimiento, como atestigua la queja del fiscal del rey en $1644^{99}$.

El estigma de la placera, y en menor medida del placero, se ha conservado en ciertas connotaciones del término. Covarrubias no lo recoge, pero sí el Diccionario de Autoridades, que no olvida que junto a la primera y aséptica acepción ("el que vende en la plaza los géneros y cosas comestibles"), el placero también es "el sujeto ocioso que se anda en conversación por las plazas"100. También la "verdulera" ha adquirido unas connotaciones semejantes. Nuestro Diccionario de la Real Academia recoge la acepción; la verdulera es la "mujer descarada y ordinaria". ¿No hay ahí seculares vinculaciones simbólicas que aún hoy se infiltran en ciertos oficios?

\section{EL PREGÓN: INSTITUCIONALIZACIÓN DE UN GÉNERO ORAL}

Para comprender el arraigo del pregón en los siglos XVI y XVII, es indispensable ponerlo en relación con su utilidad: vender y suscitar la venta oralmente en una época en que solo una minoría sabía leer y escribir. A Bartolomé Joly, de viaje por España entre 1603 y 1604, le llama la atención no solo la cantidad de frutos y otros productos que se venden en las plazas, sino también cómo se pregonan. En Valencia, escribe el consejero y limosnero del rey de Francia, "los víveres se gritan desde por la mañana, como en París, desde las cuatro de la mañana"101. La referencia a la capital de Francia no es azarosa, ya que les cries de la ville constituían algo así como un referente identitario de la capital parisina. Entre los siglos XV y XVI, los pregones de los vendedores callejeros se convirtieron en toda Europa en una especie de género folclórico, al mismo tiempo que muchos de los vendedores se constituyeron como arquetipos populares. En realidad, los pregones habían llamado la atención de autores cultos desde la Edad Media, especialmente en Inglaterra o Francia. Los gritos de París (cris de Paris) - pregones en forma de cuartetos con que los vendedores ambulantes ofrecían su mercancía en la capital de Francia-, inspiraron una gran cantidad de obras desde el siglo XIII. Guillot de Paris escribe su Dit des rues de Paris en torno a 1280, y Guillaume de la Villeneuve, en el mismo siglo, es autor de un largo poema titulado Dit des crieries de Paris. Años más tarde Clément de Janequin (nacido en 1485 y muerto en 1558) compondrá Voulez ouyr les cris de Paris?, más conocida como Los gritos de París, obra inspirada en los vendedores ambulantes de esta ciudad. Entre las más completas, destaca la obra Cris de Paris que l'on crie journellement par les rues de la dite ville, reiteradamente publicada a partir de 1584.

99 "Por auto y pregón de Corte, proveído por los Alcaldes de la Casa y Corte de V. A., está mandado que en las plazas públicas ni fuera de ellas, ninguna mujer que no fuera casada, o de cuarenta años arriba, no pueda vender la fruta ni otros mantenimientos en las dichas plazas ni en las calles, pena de cien azotes; y contraviniendo a este auto y pregón de Corte, mucho número de mujeres, mozas y muchachas, en que no concurren las calidades de dicho pregón, venden así la fruta como los demás mantenimientos, en que se siguen grandes inconvenientes" (M. Herrero, Madrid en el teatro..., p. 9).

100 Diccionario de Autoridades..., vol. 3, voz 'placero'.

101 J. García Mercadal, Viajes de extranjeros..., vol. 2, p. 714. 
También en Inglaterra encontramos pregones de vendedores callejeros londinenses en London Lackpenny, una obra satírica atribuida al poeta inglés John Lydgate, a principios del siglo XV. Numerosos géneros poéticos-musicales se inspirarán en estos pregones; madrigal, chanson, motete, etc. Incluso, surgirá una forma poético-musical específica que reproduce los cantos de los vendedores; los dominados gritos. Los pregones londinenses serán fuente de inspiración de varios músicos ingleses de los siglos XVI y XVII: Richard Dering, Thomas Weelkes, Orlando Gibbons, John Dowland, Thomas Ravenscroft o Henry Purcell.

No solo fascinará su musicalidad, también el atuendo y apariencia de los vendedores callejeros. Del siglo XIV son las primeras imágenes conocidas de pregoneros públicos en Francia ${ }^{102}$, y en torno al año 1500 ya tenemos en Francia una serie de dieciocho grabados en madera que representan diferentes tipos de mercaderes ambulantes con sus respectivos pregones: vendedores de cristales, pescaderas, vendedores de hierro viejo, de escobas, de nabos, incluso un vendedor de obleas ${ }^{103}$. En Inglaterra hay alusiones a los pregones de los pescaderos, verduleros y otros vendedores, al menos desde mediados del siglo $\mathrm{XV}^{104}$. Los diferentes vendedores, con sus característicos atuendos y pregones, constituían un mosaico no solo de la diversidad de productos y maneras de publicitarlos, sino también de los diferentes tipos provinciales, ya que cada región estaba especializada en unos tipos de servicios y productos.

En España, la cantidad de autores que se hacen eco de los pregones callejeros en todo tipo de obras, sugiere que estos se habían convertido en el siglo XVII en un género muy del gusto del público. Las escenas de venta callejera con pregones tuvieron un especial encaje en los entremeses, mucho más dados a recrear realistamente situaciones cotidianas que otros géneros dramatúrgicos ${ }^{105}$. El espectador estaba familiarizado con los pregones, muchos de los cuales identificaban a personajes folclóricos; así el ciego ("¿Quién me lleva la xácara nueva?") o el buhonero asturiano o francés ("iHilu de Flandes!"). En ocasiones, los pregones sirven para ambientar las ferias y fiestas populares que aparecen retratadas en el teatro. Es lo que hace Pedro Lanini y Sagredo en su Entremés del día de San Blas en Madrid, una fiesta de sabor casi carnavalesca, celebrada cada 3 de febrero, a la que acudían tanto los valientes y fisgonas de los barrios, como el propio Felipe IV y los nobles de la Corte.

Los escritores barrocos españoles identificaron, por lo tanto, los pregones de estos vendedores callejeros como uno de los rasgos típicos de las clases populares, en una época en que vociferar la mercancía o transmitir cualquier noticia de viva voz constituía una práctica generalizada, cotidiana. Pero enfatizaron ciertos rasgos, vinculados a la estética carnavalesca: ruptura con el decoro, inversión del orden, realismo grotesco especialmente en lo carnal (en lo sexual y en cuanto a la comida y bebida), transgresión singularmente en el verbo deslenguado y disparatado, agresividad burlesca y en general una jocosidad disparatada que era común en entremeses, mojigangas, vejámenes, comedias burlescas y otros géneros carnavalescos del Siglo de Oro ${ }^{106}$.

Si la historia, como la antropología, trata de encontrar, en cada época, la singular mezcla de constancias y rupturas, tradición e innovación, ciertos elementos de continuidad,

102 Massin, Les cris de la ville. Commerce ambulants et petits métiers de la rue, París, Gallimard, 1978, p. 33. 103 Ibídem, pp. 1-10, 33.

104 A. W. Tuer, Old London Street Cries and the Cries of To-Day, with Heaps of Quaint Cuts, Londres, The Leadenhall Press (reimpresión 1978, Londres, The Scolar Press), 1885, pp. 3-5.

105 H. E. Bergman, Luis Quiñones de Benavente y sus entremeses: con un catálogo biográfico de los actores citados en sus obras, Madrid, Castalia, 1965, p. 421.

106 J. Huerta Calvo, E. Peral Vega y J. Ponce Cárdenas, Tiempo de burlas: En torno a la literatura burlesca del Siglo de Oro, Madrid, Verbum, 2001. 
recreados en cada época con singularidades, permiten hablar de la vigencia de unas similares significaciones en torno a los vendedores y del arraigo de una auténtica tradición pregonera. Si los códigos jocosos y apicarados son consustanciales a muchas de las recreaciones literarias áureas, aún pregona irónicamente un joven gitano en un mercadillo sevillano: “iMe cuesta más venderlas que robarlas!”, mientras otra vocifera burlón; "¡Melones de Gandía, se roban de noche y se venden de día!". Y aún hoy pueden escucharse pregones que juegan con la ambivalencia carnal, como la de una vendedora de higos andaluza, en cuyo lenguaje puede uno disfrutar de una misma y fecunda tradición cómica popular: "¡Ya llegó la mujer del jigo gordo, / Del jigo gordo, igordo y colorao!".

\section{CONCLUSIONES}

La literatura de los siglos XVI y XVII recrea la mala fama de los vendedores callejeros, estigma que puede rastrearse también en otros documentos, como leyes, informes de las autoridades, tratados o diccionarios. Al secular desdén por los trabajos manuales y en particular por los comerciantes, se le unían otros factores como la pobreza de la mayoría de los vendedores callejeros, su carácter itinerante, su condición de emigrantes o minorías étnico-religiosas, así como el hecho de que trabajaran en muchos casos con productos considerados no solo ínfimos sino impuros. Buhoneros gabachos, trajineros moriscos, aguadores asturianos o herreros gitanos cristalizaron como arquetipos sociales, que convivían —en la plaza, en el mercado y muy especialmente en la fiesta- con decidores de buenaventura, charlatanes, titiriteros, ciegos y todo tipo de personajes errabundos y apicarados. La venta callejera se asociará a lo vil, al vagabundeo, al engaño, a la mala vida y a las expresiones groseras de las clases populares. Entre estas destaca particularmente el pregón, convertido en género folclórico-literario de la misma manera que el vendedor callejero cuajará como tipo popular. Insertos en la cultura cómica popular, los vendedores, su estilo de vida y formas de expresión constituirán un recurso literario ambivalente: las trifulcas de las mondongueras y otras placeras, como los pregones a través de los cuales vociferan su mercancía, se considerarán muestras de zafiedad y grosería, pero también del ingenio socarrón y la ambivalencia carnavalesca que juega a ensalzar y degradar grotescamente a la vez todo lo considerado bajo, y muy singularmente lo carnal, en su doble acepción que remite al sexo y a la comida. En definitiva, el estudio histórico-cultural del vendedor callejero en los siglos XVI y XVII, demuestra que este encarna, en diversos textos culturales, el estigma del extraño, el marginal, el impuro, el incivilizado y el embaucador, pero también inspira la utopía de un mundo de superabundancia, glotonería, libertad y risa.

\section{BIBLIOGRAFÍA}

Arce de Otálora, J. de, Coloquios de Palatino y Pinciano, 2 vols., Madrid, Fundación José Antonio de Castro, Turner, 1995.

Armesto y Castro, G. de, Verdores del Parnaso, en diferentes entremeses, vayles, $y$ Mogiganga, escritos por..., Pamplona, Juan Picón, Impressor del Reyno, 1697.

Autoridades, Diccionario de, 3 vols., Madrid, Gredos, 1990.

Bajtin, M., La cultura popular en la Edad Media y en el Renacimiento. El contexto de François

Rabelais, Madrid, Alianza Universidad, 1995.

Bennassar, B., La España del Siglo de Oro, Madrid, RBA, 2006.

Bergman, H. E., Luis Quiñones de Benavente y sus entremeses: con un catálogo biográfico de los actores citados en sus obras, Madrid, Castalia, 1965.

Bergman, T., "Transversality, criminality, and the gypsy in Spanish baroque teatro breve", 
Journal of Spanish Cultural Studies, 13:3 (2012), pp. 276-291.

Bravo-Villasante, C., Villancicos del siglo XVII y XVIII, Madrid, Editorial Magisterio, 1978.

Buezo, C. (ed.), Mojigangas dramáticas (siglos XVII y XVIII), Madrid, Cátedra, 2005.

Burke, P., La cultura popular en la Europa Moderna, Barcelona, Altaya, 1977.

Calderón de la Barca, P., Obras completas. Dramas, vol. 1, Madrid, Aguilar, 1966.

Campo, A. del y Ruiz Morales, F. C., "Galería de asustaniños de carne y hueso. Miedo y fascinación en torno a las categorías de la anormalidad en Andalucía", Revista de Dialectología y Tradiciones Populares, 70.2 (2015), pp. 547-568.

Campo, A. del y Cáceres, R., Historia cultural del flamenco. El barbero y la guitarra, Córdoba, Almuzara, 2013.

Campo, A. del, "El culo en el cancionero de tradición popular. Realismo grotesco, escatología y obscenidad en contextos festivos liminares", Revista de Dialectología y Tradiciones Populares, 68, 2 (2013), pp. 489-516.

-2018, Elogio de la locura sevillana. Necios, inocentes y bufones en la ciudad de la gracia (siglos XV a XIX), Sevilla, Aconcagua.

Caro Baroja, J., Los moriscos del Reino de Granada. Ensayo de historia social, Madrid, Istmo, 2000.

Cervantes, M. de, Novelas ejemplares, 2 vols., Madrid, Cátedra, 2007.

- Obras completas, 2 vols., Madrid, Aguilar, 2003.

Chalmeta, P., El zoco medieval. Contribución al estudio de la historia del mercado, Almería, Fundación Ibn Tafayl de Estudios Árabes, Fundación Cajamar, 2010.

Chevalier, M., Tipos cómicos y Folklore. Siglos XVI y XVII, Madrid, Edi-6, 1982.

Clebert, J. P., Los gitanos, Barcelona, Aymá editora, 1965.

Cotarelo y Mori, E., Colección de Entremeses, Loas, Bailes, Jácaras y Mojigangas desde fines del siglo XVI á mediados del XVIII, 2 vols., Madrid, Lasa Editorial Bailly/Bailliére, 1911.

Covarrubias Orozco, S. de, Tesoro de la Lengua Castellana o Española, Madrid, Castalia, 1995.

Darnton, R., La gran matanza de gatos y otros episodios en la historia de la cultura francesa, México, FCE, 2006.

Douglas, M., Pureza y peligro. Un análisis de los conceptos de contaminación y tabú, Madrid, Siglo Veintiuno, 1973.

Duroux, R., "España país tradicional de inmigración. Los auverneses de Castilla y sus fuentes", Migraciones \& Exilios: Cuadernos de la Asociación para el estudio de los exilios y migraciones ibéricos contemporáneos, 1 (2000), pp. 97-127.

Fernández Chaves, M. F., y Pérez García, R. M., En los márgenes de la ciudad de Dios. Moriscos en Sevilla, Valencia, Publicacions de la Universitat de València, Editorial Universidad de Granada, Servicio de Publicaciones de la Universidad de Zaragoza, 2009.

Fontaine, L., History of Pedlars in Europe, Durham, Duke University Press, 1996.

García Mercadal, J., Viajes de extranjeros por España y Portugal, 6 vols., Salamanca, Junta de Castilla y León, 1999.

Geertz, C., La interpretación de las culturas, Barcelona, Gedisa, 1987.

Goffman, E., Estigma. La identidad deteriorada, Buenos Aires, Amorrortu editores, 1970.

Gracián, B., El Criticón, Madrid, Cátedra, 1996.

Herrero, M., Ideas de los españoles del siglo XVII, Madrid, Editorial Gredos, 1966.

— Madrid en el teatro, Madrid, Instituto de Estudios Madrileños, CSIC, 1963. 
- Oficios populares en la sociedad de Lope de Vega, Madrid, Editorial Castalia, 1977.

Holleran, C., Shopping in ancient Rome. The Retail Trade in the Late Republic and the Principate, Oxford, Oxford University Press, 2012.

Huerta Calvo, J., Peral Vega, E. y Ponce Cárdenas, J., Tiempo de burlas: En torno a la literatura burlesca del Siglo de Oro, Madrid, Verbum, 2001.

Jiménez Mancha, J., Asturianos en Madrid. Los oficios de las clases populares (siglos XVIXX), Gijón, Muséu del Pueblu d`Asturies, 2007.

La vida y hechos de Estebanillo González, 2 vols., Madrid, Cátedra, 1990.

López de Ayala, P., Rimado de Palacio, Madrid, Castalia, 1987.

Madroñal, A., "Juan Francés, vida entremesil de un personaje literario", en M. C. García de Enterría y A. Cordón Mesa (ed. lit.), Actas del IV Congreso Internacional de la Asociación Internacional Siglo de Oro (AISO), vol. 2, Alcalá de Henares, 1998.

Magaldi, E., "Il commercio ambulante a Pompei", Atti della Academia Pontaniana, 60, 2. 35 (1930).

Marcial, M. V., Epigramas, Zaragoza, Institución Fernando el Católico (CSIC), 2003.

Massin, Les cris de la ville. Commerce ambulants et petits métiers de la rue, París, Gallimard, 1978.

Moncada, S., Restauración política de España y deseos públicos, Madrid, Juan de Zúñiga, 1746.

Moreto, A., Comedias escogidas, Madrid, BAE XXXIX, Ediciones Atlas, 1950.

Nicolini, F., Aspetti della vita italo-spagnuola nel Cinque e Seicento, Nápoles, Alfredo Guida, 1934.

Perry, M. E., Hampa y sociedad en la Sevilla del Siglo de Oro, Sevilla, Ensenada, 2012.

Quevedo, F. de, La hora de todos y La fortuna con seso, Madrid, Castalia, 2009.

Quiñones de Benaventes, J., "Discurso sobre los gitanos", en F. Grande, Memoria del Flamenco, Madrid, Alianza Editorial, 1999.

Rabelais, F., Pantagruel, Madrid, Cátedra, 2003.

Ruby, P. de, La vie généreuse des mercelots gueux et bohémiens, París, Edicions Allia, 1999.

Sales Mayo, F. de, El gitanismo, historia, costumbres y dialecto de los gitanos, Madrid, Librería de Victoriano Suárez, 1870.

Santos, F., El no importa de España y La verdad en el potro, Londres, Tamesis Books Limited, 1973.

Semanario Erudito que comprende varias obras inéditas, críticas, morales, instructivas, políticas, históricas, satíricas y jocosas de nuestros mejores autores, vol. 9, Madrid, Blas Román, 1788.

Starkie, W., 1944, Don Gitano. Aventuras de un irlandés con su violín en Marruecos, Andalucía y en La Mancha, Barcelona, Ediciones Pal-las.

Suárez de Figueroa, C., Plaza universal de todas ciencias y artes, parte traducida del Toscano, y parte compuesta por el doctor... Madrid, Luis Sánchez, 1615.

Tirso de Molina (Gabriel Téllez), Cigarrales de Toledo, Madrid, Luis Sánchez, 1624.

- Obras dramáticas completas, vol. 3, Madrid, Aguilar, 1968.

Tuer, A. W., Old London Street Cries and the Cries of To-Day, with Heaps of Quaint Cuts, Londres, The Leadenhall Press (reimpresión 1978, Londres, The Scolar Press), 1885. Vega, L. de, El acero de Madrid, Madrid, Castalia, 2000.

- Las ferias de Madrid y La Vitoria de la Honra, Valencia, Estudios de Hispanófila, 1977.

- Obras escogidas, vol. 1, Madrid, Aguilar, 1966. 
Vélez de Guevara, L., Más pesa el rey que la sangre y Reinar después de morir, Madrid, Akal, 2002.

Vicente, G., Teatro castellano, Barcelona, Crítica, 1996.

Zabaleta, J. de, El día de fiesta por la mañana y por la tarde, Madrid, Editorial Castalia, 1983. 